Orbis Tertius, vol. XXIV, $\mathrm{n}^{\circ}$ 30, e122, noviembre 2019-abril 2020. ISSN 1851-7811

Universidad Nacional de La Plata

Facultad de Humanidades y Ciencias de la Educación

Centro de Estudios dđeoría y Crítica Literaria

\title{
Um filósofo alemão afrancesado: a recepção editorial de Nietzsche na Argentina (1890-1930)
}

A german franchified philosopher: the editorial reception of Nietzsche in Argentina

Antonio Vinicius Lomeu Teixeira Barroso

Universidad Nacional de La Plata, Argentina

alomeu@fahce.unlp.edu.ar

\section{Resumo:}

O presente artigo tem como objetivo investigar como se deu a recepção do filósofo alemão Friedrich Wilhelm Nietzsche entre 1890 e 1930 na Argentina, a partir do ponto de vista de uma historia das ediçóes e da circulação de internacional de textos. Desse modo, daremos ênfase ao trabalho de analise das primeiras obras do filósofo que foram importadas, traduzidas e publicadas no país, destacando a importância da recepção dos textos franceses. Procuramos contribuir, portanto, para uma historia das idéias e da filosofia na Argentina, a partir de um ângulo material, na medida em que este nos oferece uma interessante perspectiva para se compreender as condições de circulação e formas de valoração da obra de Nietzsche.

Palavras-Chave: Nietzsche, Argentina, Recepção de idéias, Historia editorial.

\section{ABstract:}

This article aims to investigate the reception of the German philosopher Friedrich Wilhelm Nietzsche between 1890 and 1930 in Argentina, from the point of view of a history of ideas and the circulation of texts internationally. Thus, we will emphasize the work of analyzing the first works of the philosopher that were imported, translated and published in the country, highlighting the importance of receiving the French texts. We seek, therefore, to contribute to a history of ideas and philosophy in Argentina, from a material angle, insofar as it offers us an interesting perspective to understand the conditions of circulation and ways of valuing the work of Nietzsche.

KEYWORDS: Nietzsche, Argentina, Reception of ideas, Publishing history.

\section{INTRODUÇÃO}

Friedrich Nietzsche é considerado por muitos intelectuais do século XX e XXI um dos grandes pensadores do mundo contemporâneo, cujas ideias tiveram ampla ressonância em distintas ideologias e em diversas áreas do saber. De acordo com Paul Ricœr, junto a Karl Marx e Sigmund Freud, Nietzsche seria um dos grandes mestres da suspeita, na medida em que fundamenta seu pensamento em uma forte critica da sociedade e seus valores modernos. Jurgen Habermas considera o filósofo alemão o principal fundador da pós-modernidade, por seu forte combate aos pressupostos iluministas da razão, evolução e verdade. Um dos seus intérpretes mais ilustres, Martin Heidegger, chega a afirmar que todos os que hoje pensam o fazem à luz e à sombra de Nietzsche, seja "a favor" ou "contra ele" (2014, p. 124). Mediante a importância que o pensamento nietzschiano adquiriu ao longo do século XX e a carência de estudos sobre a sua leitura e apropriação no hemisfério sul, tentaremos compreender como ocorreu sua "primeira" difusão na Argentina tendo em vista que a historia da recepção na America Latina de suas ideias é quase inexistente (Cragnolini, 2001, p. 10).

Por meio da história editorial, do comércio de livros, da relação entre autores e editores, pretendemos contribuir com uma nova perspectiva sobre a história das ideias no continente sul-americano, na medida em que diferentes edições de um mesmo autor sugerem formas diferenciadas de recepção ou mesmo de incorporação de seu pensamento. ${ }^{1}$ Essa perspectiva editorial costuma estar presente na historia das idéias e dos intelectuais como mais um dado entre outros, ou como parte da produção de um autor, mas em poucas oportunidades como um problema analítico em si, necessário para compreender as formas de circulação e apropriação cultural. 
O período no qual Nietzsche escreveu seus textos e publicou suas obras compreende os anos de 1872 e 1888. Após sua morte, em 1900, muitas edições e reedições de seus livros foram publicadas, algumas de fragmentos póstumos, em diferentes países e em diferentes línguas. A manipulação de seus escritos, assim como traduções e edições controvérsias de seus livros foram e continuam sendo um grande tema de discussão entre tradutores, filósofos, biógrafos e historiadores. Muitas de suas obras, inclusive, serviram de base ideológica para o nazi-fascismo na Europa através de um trabalho arbitrário de mutilação e descontextualização de seus escritos. ${ }^{2}$

Deixando essas polêmicas acerca da manipulação de suas obras de lado, tentaremos compreender de que maneira o pensamento do filósofo alemão chegou à Argentina, problematizando alguns pontos importantes, embora em grande medida ignorados, na pesquisa sobre sua recepção: Quais são suas primeiras edições que chegam ao país? Em que idiomas estavam escritos esses livros ou textos? Quais as primeiras traduções que chegaram? Nietzsche era lido através de obras de comentadores ou diretamente?Tendo essas perguntas como ponto de partida, tentaremos reconstruir o caminho feito pelos livros de Nietzsche em território sulamericano.

\section{O MERCADo EDITORIAL ARGENTINO NO FIM DO SÉCULO XIX E INICIO DO SÉCULO XX}

As duas últimas décadas do século XIX na Argentina estão marcadas pelo surgimento de um mercado editorial moderno, embora a formação desse mercado se revelasse um processo ainda bastante incipiente. Ao longo dos anos de 1880, a produção de livros e folhetos se duplicou, acompanhando o crescimento populacional de Buenos Aires, cidade que concentrava o processo de formação do mercado moderno de edições no país (Pastormerlo, 2015). Durante esse período, ampliou-se o publico leitor e expandiu-se a cultura letrada, além de aumentarem consideravelmente o numero de editoras e de publicações, principalmente de livros de ensino e textos criollistas (Aguado, 2006). Esse aumento do numero de leitores foi impulsionado, principalmente, pelas campanhas da alfabetização e escolarização levadas a cabo pelo Estado, tais como a Ley de Educación Comúde 1884 e a Ley Láinez de 1905. Pode-se afirmar que ao longo do século XIX a formação de comunidades de leitores foi possível, em grande medida, graças à forte expansão transatlântica da produção intelectual e editorial francesa que implicava a tradução, adaptação e produção original de impressos na França (Sora, 2011, p. 15).

Nos primeiros anos do século XX, se evidenciou ainda o inicio da organização do espaço editorial e da consolidação do mercado de livros de baixo custo, isto é, de folhetins estrangeiros e nacionais e da literatura gauchesca. Ate 1910, houve uma gradual substituição de livros impressos no estrangeiro e apareceram pela primeira vez edições de literatura culta com grande tiragem. No entanto, seria somente entre 1920 e 1937 que apareceria a figura do editor moderno e surgiria uma serie de projetos editoriais que buscavam suprir a demanda de um publico leitor já diversificado e ampliado. Todo este processo de mudança na Argentina foi lento e, enquanto se desenvolvia o mundo editorial local durante as primeiras décadas do século XX, a maioria das obras que circulavam vinham impressas de diferentes cidades da Espanha ou de Paris (Valinoti, 2016, p. 35).

Em meio a esse contexto editorial, desembarcaram obras de pensadores estrangeiros que tiveram grande circulação entre o crescente publico leitor argentino, sobretudo da Capital Federal. Essa chegada de novos livros vindos do exterior ocorreu, em grande medida, através das "multidões" de imigrantes que traziam consigo uma grande quantidade de obras de autores estrangeiros por meio da importação de livros e revistas por editoras nacionais e internacionais; e também através da ainda iniciante edição de livros estrangeiros que começavam a ser traduzidos e publicados em território argentino (Caeiro, 2015, p. 94).

Dentre esses livros novos que começam a circular no país, estavam os de Friedrich Nietzsche. Muitas alusões ao seu pensamento podem ser detectadas principalmente em revistas e periódicos culturais e também em citações feitas a partir de traduções de obras em francês, entre os anos de 1880 e 1945 (Cragnolini, 2001, p. 
107). As obras do filósofo alemão publicadas pela editora parisiense Mercure de France, como analisaremos de maneira mais aprofundada adiante, foram largamente citadas entre os intelectuais argentinos nesse momento.

${ }^{3}$ Essas edições importadas foram objeto de vastas leituras e figuram nas notas de rodapé e bibliografias de muitos livros dos primeiros leitores de Nietzsche em grande parte da America do Sul.

\section{Os Primeiros registros das edições de Nietzsche na Argentina}

De acordo com Mónica Cragnolini, as primeiras obras do filósofo alemão foram lidas em francês, através de traduções de Henri Albert, assim como por meio de traduções desse idioma ao espanhol (Cragnolini, 2001, p. 113). ${ }^{4}$ Em 1909, a revista portenha Nosotros publicou em varias entregas a tradução de Ecce Homo, realizada por Enrique Banchs, poeta argentino de grande influencia germanista, tomando como referencia a edição francesa de Albert publicada pela editora Mercure de France meses antes. Seria somente a partir de 1932 que o leitor argentino contaria com uma tradução para o espanhol das Obras Completas trabalho feito por Ovejero e Maury. ${ }^{5}$ Tal tradução considerada por muitos estudiosos como "defeituosa" foi, segundo Cragnolini, a única referencia da obra total de Nietzsche em espanhol que circulou por vários anos na Argentina.

O trabalho de algumas traduções ao espanhol, no entanto, já haviam sido iniciados pela editora madrilena La España Moderna, em 1900, com a publicação do Assim Falou Zaratustra, obra traduzida por Juan Fernandez. Mais tarde, a editora espanhola iria traduzir e publicar outros escritos de Nietzsche como Para além de bem e mal (1901), e a Genealogia da Moral (1901), ambas sem mencionar o tradutor. Segundo Gonzalo Sobejano, essas versões são isentas de prólogo, contêm pouquíssimas notas e não oferecem particularidade alguma de atenção. Ao longo da primeira década do século XX a editora espanhola ainda iria traduzir e publicar Aurora (1902), os últimos panfletos que reúnem $O$ caso Wagner, Nietzsche contra Wagner, O crepúsculo dos ídolos e O Anticristo (1904); e A gaia Ciência (1905-1906). Todas elas foram assinadas por Luciano de Mantua, "pseudônimo que não podemos decifrar, mas que nesse caso a ignorância não é grave, pois o tradutor fez um trabalho meramente funcional” (Sobejano, 2004, p. 74, in: Drews, 2014, p. 197). Finalmente, em 1907, La España Moderna publica sua ultima obra do filósofo, $O$ andarilho e sua sombra, como segundo volume de Humano demasiado Humano.

Essas traduções da editora espanhola, de acordo com Pablo Drews, tiveram um prestígio muito grande na cultura rio-platense, melhorando o acesso dos leitores hispânicos às obras de Nietzsche e produzindo uma mudança na própria maneira como se contemplava os seus livros. Como nos aponta Sergio Sanchez, durante a primeira metade do século XX, "a influência de Nietzsche no mundo latino-americano tem sido mais notada no campo da literatura que no da filosofia" (Sanchez, 2013, p. 62) o que seria "uma característica geral da cultura e da recepção das ideias filosóficas em nossa América” (p. 63). Se com a Mercure de France as obras de Nietzsche eram consideradas, antes de tudo, literárias, com La España Moderna começaram a ser vistas a partir de uma perspectiva mais filosófica, tendo em vista que a ultima editora era "mais afim com temas da filosofia feita" atraindo um publico de estudiosos e interessados em leituras filosóficas (Drews, 2014, p.196-197). ${ }^{6}$

Outra editora mencionada por Drews, a Sempere, de Valencia, foi fundamental no processo de difusão das obras de Nietzsche entre os leitores de língua espanhola. A editora valenciana publicou, entre os anos de 1906 e 1910, inúmeras traduções feitas por Pedro Gonzáles-Blanco, das obras Assim falava Zaratustra, A genealogia da Moral, Aurora, A gaia ciência e O Anticristo. O caso Wagner, Nietzsche contra Wagner, Miscelânea de opinióes e sentenças, O Crepúsculo dos idolos, Para além de bem e mal, A origem da tragédia, Humano demasiado Humano e $O$ Andarilho e sua sombra. Sobre essas traduções, feitas diretamente de traduções da Mercure de France, Sobejano afirma que "poucos temos a dizer. Onde são mais toleráveis não passam da correção fria de mera cópia; porém, são inúmeros os casos em que o tradutor abrevia o texto, 
omitindo frases embora passagens de relativo comprimento, já guiando-sepela significação de conjunto sem atender à letra" (Sobejano, 2004, p. 74, in: Drews, 2014, p. 198).

A circulação dos livros da Sempere, no Rio da Prata, teve grande impulso através do trabalho editorial de Orsini Bertani, editor uruguaio que atuou na difusão das obras de importantes autores europeus em livrarias e bibliotecas de grandes cidades da America do Sul como Montevidéu, Lima e Buenos Aires (Drews, 2014, p. 196-197). Bertani, considerado o "primeiro editor puro" do Uruguai, importava, vendia e editava livros, apostando na formação de um catalogo de livros independentes da figura do livreiro e do impressor e desenhando uma política de acordo com a modernização cultural no Rio da Prata. Desse modo, o editor uruguaio "acompanhava a abertura ao mundo europeu mediante a importação de livros que renovavam o pensamento e as letras, ajustando os relógios da contemporaneidade e do novo" (Rocca, 2012, p. 6). Ademais, como destaca Horacio Tarcus, a Biblioteca Blanca, uma editora que pertencia à valenciana Sempere, editou centenas de títulos em edições populares que eram importadas por distribuidores e livreiros argentinos, de tal maneira que acabou sendo:

(...) la verdadera biblioteca obrera del siglo XX, en la cual juntos a textos de Engels y el resumen de El Capital de de Deville, se publicaba a Büchner, Comte, Spencer y Haeckel; al lado de Vandervelde, Berstein, Jaurès y Labriola se editaba a Sorel y a los 'sindicalistas', a Bakunin, Faure y Kropotkin, a Max Nodau y a Mazzini, a Gorki y Anatole France, a Tolstoy a Zola, a Ibsen y D'Annunzio, a Haine y Max Stirner, a Wagner, Nietzsche y Schopenhauer (Tarcus, 2007, p. 332)

Es importante destacar que essas traduções ao espanhol publicadas pela editora Sempere foram feitas diretamente de traduções da Mercure de France, o que revela a mediação francesa até mesmo nas obras traduzidas ao idioma nativo argentino (Drews, 2014, p. 198). A editora Sempere foi a editora em espanhol mais lida entre os argentinos nesse momento, sobretudo entre os intelectuais anarquistas, pois possuía uma edição com preços mais populares e acessíveis. Essas edições, no entanto, modificaram o sentido de muitas frases e sentenças além de possuírem inúmeras falsificações e erros nas traduções (Sobejano, 2004, p. 80). As traduções dos livros ao espanhol "ejecutadas muchas de ellas a través del francés por publicistas de escasa o nula competencia filosófica y literaria" geravam desconfiança no leitor, pois do ponto de vista editorial apresentavam alguns problemas como "la impresión negligente y a reimpresiones disfrazadas, [...] estropeadas por la incuria tipográfica, los errores errantes, la falta de orden y la exigüidad o ausencia de notas aclaratorias" (Sobejano, 2009). Talvez por estes motivos, as traduções ao francês de Albert continuavam sendo procuradas pelos interessados no filósofo alemão.

O papel desempenhado pelos próprios leitores de Nietzsche na divulgação de novas edições de suas obras também é algo importante a ser destacado. Num artigo dedicado ao filósofo, publicado no periódico portenho La Nación de 2 de abril de 1894, o poeta nicaragüense Ruben Dario escreveu o seguinte comentário: "A pesar de Henri Albert y los nietzschistas de la juventud francesa, la obra de Nietzsche es conocida muy escasamente" (Dario, 1894, p. 268). Podemos perceber, nessa passagem, como Dario reconhece o esforço do tradutor francês em difundir o pensamento nietzschiano. Mais adiante, sobre a importância da obra de Henri Albert, destacara:

[...] quienes deseen conocer fundamentalmente a Federico Nietzsche pueden procurarse las obras originales o las traducciones francesas, los estudios de Henri Albert, y sobre todo, la reciente obra de Jorge Brandes, Hombres y Obras, en que están estudiadas profundamente la personalidad y las doctrinas del filósofo alemán (Dario, 1894, p. 269).

Nesse trecho, além de serem indicadas as já mencionadas traduções francesas e a obra critica de Albert, é sugerido o livro de Jorge Brandes, Homens e Obras, que contém dados sobre a personalidade e doutrinas do filósofo alemão. Dario se refere ao critico literário dinamarquês responsável pela divulgação do pensamento nietzschiano em grande parte da Europa setentrional, que escreveu alguns textos de grande repercussão sobre o filósofo, tais como "Radicalismo aristocrático: um ensaio sobre Nietzsche", 7 publicado em 1890, pela revista alemã Deutsche Rundschau, e o texto Hombres y obras mencionado por ele, sobre o qual não encontrou-se registros sobre a edição a qual ele se refere. ${ }^{8}$ Provavelmente, Dario alude à obra de Brandes, 
através da leitura de um livro de Henri Albert, Nietzsche y Georges Brandes, que foi citada no próprio artigo do La Nación. O que chamou atenção mais uma vez, no entanto, foi a importância dada por Dario aos comentadores e críticos de Nietzsche que chegavam às suas mãos através de versões em francês e seu conhecimento de textos editados na Europa que ainda não circulavam em seu país.

Assim como Dario, vários outros leitores argentinos de Nietzsche tiveram acesso as suas obras através dessas versões francesas. Jose Ingenieros realizou suas leituras do pensador alemão por meio da Revue Blanche que chegava ao Ateneo de Buenos Aires, por volta do ano de 1898 (Ponce, 1948, p. 28). Ricardo Rojas, em seu livro La Restauración Nacionalista, publicado pela primeira vez em 1909, cita a obra com o título em francês, Considérations inactuelles (David Strauss, De l'utilité et des inconvénients des Études historiques), publicada pela Mercure de France, quando reflete sobre o ensino de historia nas instituições argentinas (Rojas, 2010, p. 268). Como já foi dito anteriormente, Enrique Banchs traduz ao espanhol a obra Ecce Hommo, a partir da tradução francesa de Albert e a publica na revista portenha Nosotros em 1909.

Mesmo com traduções disponíveis em espanhol, a partir de 1900, no entanto, Nietzsche continuou sendo lido predominantemente em francês, isso se deve, em alguma medida, à forte tradição francófona de muitos intelectuais argentinos e latino-americanos. As versões francesas de alguns autores foram as que mais circularam e serviram como fonte de leitura na Argentina, e em grande parte da America do Sul. A seguir, tentaremos compreender outros motivos que levaram a grande circulação dessas traduçóes entre o publico argentino, investigando, sobretudo, o papel desempenhado pela editora francesa no mercado editorial e como suas edições das obras do filósofo alemão tiveram repercussão no país.

\section{A Mercure de France e a renovação literária}

A Mercure de France, fundada originalmente como revista literária por Jean Donneau de Visé, em 1672, foi criada com o objetivo inicial de informar a sociedade elegante sobre a vida na corte e sobre os debates artísticos e intelectuais parisienses. De 1672 a 1674, circulou com o nome Mercure Galant, mudando para Nouveau Mercure Galant em 1677 e, em 1724, para Mercure de France. A revista foi descontinuada entre 1811 e 1815 e encerrada em 1825. O nomefoi retomado pelo editor e escritor Alfred Vallette em 1890 para dar nome a uma revista literária de inspiração simbolista. Ao longo desta década a revista se apresentou como uma espécie de ferramenta de consolidação de novos pensamentos e de sua conseqüente reprodução na literatura, refletindo em suas paginas tendências como o misticismo e o ocultismo, além do sentimento fin-de-siecle de época (Lopes, 2014, p. 3).

Em janeiro de 1890, no primeiro volume do periódico, Vallette apresenta seu principal objetivo com a publicação:

Vê-se que em tudo, em todos os lugares, e em todos os níveis sociais, há uma evolução rápida, como se via há quase vinte anos. Mas, ora em respeito à tradição, ora em adulação de um público inconscientemente hipócrita, a Imprensa se cala, naturalmente, diante do cerne das questões espinhosas. O que cada um pensa e o que ninguém organiza, são essas idéias paradoxais e subversivas, em 1890, codificadas em 1900; isto seria-nos agradável de redigir. (1890, p. 3).

De acordo com Camila Lopes, em sua primeira edição da revista, o editor francês manifestava o desejo de renovação literária e a ambição de diferenciar-se dos outros periódicos

[...] entre os três objetivos os quais um periódico literário pode propor - ou ganhar dinheiro, ou agrupar autores em comunhão estética que forma escola e que se esforça ao proselitismo, ou enfim publicar obras puramente artísticas e de concepções suficientemente heterodoxas para não serem, de modo algum, acolhidas por publicações que contam com a clientela - é este último escolhido por nós, conhecendo, de resto, especuladores muito deploráveis para esperar a metamorfose de nossos escritos em ouro, e sabendo serem inalcançáveis, nesse período transitório que atravessamos, os elementos de uma escola literária (Vallette, 1890, p. 3). 
Se examinarmos textos publicados nos anos seguintes por outros colaboradores, percebemos a importância dada ao problema do revigoramento da produção literária européia, e também das manifestações artísticas. Traduções de autores como Edgar Alan Poe, Charles Baudelaire e até mesmo criticas de obras de Van Gogh foram publicadas e apresentadas pela Mercure de France como tendências renovadoras que poderiam servir aos escritores franceses, alternativas às correntes naturalistas, cientificistas e positivistas do momento. Nesse contexto, em janeiro de 1893, num artigo da revista francesa, Albert apresenta Nietzsche associando sua filosofia ao desejo de renovação do final do século XIX

Nietzsche prevê a aurora vindoura de uma cultura nova, não de uma cultura nacional, mas expressamente européia. Agora, a elite das nações já não mais conhece fronteiras - os homens superiores de todos os países se sentem compatriotas, aliados. Esses bons Europeus serão a casta futura que reinará na Europa, casta estrangeira, tanto no vão patriotismo democrático ou monárquico como no socialismo, na anarquia e no niilismo (Albert, 1893, p. 52).

O texto intitulado Friedrich Nietzsche, apresenta o filósofo em meio a outros artigos dedicados a critica de artistas, e escritores da literatura européia. Com efeito, a revista não se dedicava tradicionalmente ao exame de filósofos, tendo em vista que estava associada mais ao simbolismo literário francês. No entanto, a Mercure de France no referido artigo de 1893 e em outros, ao longo da década, demonstrou um crescente interesse no pensamento do filósofo. A revista seria uma das introdutoras de Nietzsche na cena cultural francesa e suas traduções que, seriam publicadas cinco anos mais tarde, foram lidas por uma quantidade considerável de escritores argentinos, os quais se apropriaram de Nietzsche num sentido literário, mais do que propriamente filosófico. ${ }^{9}$

A partir de 1894, a revista francesa se lançaria ao projeto de edição de livros. Em 1898, começou a publicar as obras de Nietzsche, traduzidas pelo germanista francês Henri Albert: Ainsiparlait Zarathoustra (1898); Le Crépuscule des idoles: Le Cas Wagner: Nietzsche contra Wagner: L'Antéchrist (1899); Pages choisies (1899); La Généalogie de lamorale (1900); Aurore (1901); Le Gai Savoir (1901); Le voyageur et sonombre: Opinions et sentences mêlées (1902); La volonté de puissance (1903); Considérations inactuelles (1907-1922); Ecce homo (1909). Todas essas obras foram publicadas pela editora parisiense, com exceção de Pages choisies fazem parte da coleção Oeuvres complètes de Frédéric Nietzsche, e tiveram um papel fundamental na difusão das obras de Nietzsche no meio intelectual francês (Frezzatti, 2012, p. 78). ${ }^{10} \mathrm{O}$ texto escrito por Albert citado por Dario, no entanto, foi publicado antes mesmo dessas edições na revista Revue Blanche, em 1894, intitulado Les CEuvres complètes de Nietzsche (pour Le cinquantième anniversaire de as naissance), no qual o francês anuncia esse projeto de tradução e apresenta de forma breve dados sobre o filósofo alemão.

Por meio dos inúmeros ensaios, traduções, e revisões de livros, Albert acabou se tornando a referencia principal de Nietzsche na França na década de 1890 e 1900 (Forth, 1993, p. 114). O entusiasmo de Albert por Nietzsche já pode ser percebido em 1892 quando em uma revisão do livro de Max Klinger afirma que "alguém se curva diante de Klinger como se curva diante de Nietzsche, cheio de admiração, embora muitas vezes sem entendê-lo" (Albert, 1892, p. 131). A partir de 1893, Albert vai expressar sua admiração em diversos ensaios na Mercure de France onde constantemente se referia ao alemão como "mestre" ou "professor". Em vez de ater-se ao puro devaneio estético de algumas interpretações decadentes do momento, Albert preferiu retratá-lo como um "visionário intuitivo do futuro, Nietzsche, o libertador!" (Albert, 1893, p.65). Assim como muitos intelectuais do período, tais como Georges Sorel, Daniel Halevy, Eugene de Roberty, e George Palante, Albert interpretou o pensamento nietzschiano através de um viés de esquerda, como um socialista cujas idéias iriam libertar os proletários de seus grilhões (Forth, 1993, p. 115). Segundo Albert, se os pobres tivessem acesso ao pensamento nietzschiano "os mártires do trabalho, o povo verdadeiro, talvez tivessem previsto a força abundante para o futuro ainda adormecida neles” (Albert, 1893, p. 172). Desse modo, de acordo com a interpretação de Albert, o filósofo alemão era um crítico da classe média, da burguesia fútil, bem alimentada e satisfeita, aos quais se referia como "pessoas ordinárias", 'massas", a "ralé" (Albert 1893, p. 172). Além disso, Albert, um alsaciano germanófobo, via em Nietzsche um pensador anti-germanista cujo 
pensamento possuía inclinações francesas explícitas. Isso torna-se evidente com a rápida tradução de diversos aforismos e excertos de Nietzsche que exaltam a cultura francesa e atacam a alemã, a tradução e publicação do capítulo Povos e Pátrias em 1897 e sua falta de vontade de publicar uma edição realmente completa da obra do filósofo (Verbaere, 2008, p. 609). O Nietzsche de Albert era visto ainda como um adversário dos próprios filósofos em geral, muito mais próximo aos círculos literários do que aos filosóficos (Verbaere, 2008, p. 609-610).

Essas edições publicadas na França por Albert estão no bojo da "moda Nietzsche" que se difundiu amplamente no país desde a década de 1890 até o ano de 1914 (Frezatti, 2012, p. 60.). Nota-se nesse período, no ambiente intelectual francês, uma intensa preocupação em discutir o pensamento nietzschiano que pode ser detectada em artigos de periódicos de grande circulação, citações em poemas e contos. Segundo Schmigalle (2018) houve na França e na Bélgica, durante os anos de 1890-1914, mais de 1100 referencias a Nietzsche na língua francesa. Dentre elas, 47 obras consagradas ao filósofo, mais de 600 artigos e estudos e o restante o citavam em textos que falavam de outros autores. De todos os artigos que evocam Nietzsche em francês, 51, 7\% foram publicadas por 6 revistas, e a Mercure de France ocupava o primeiro lugar (Schimigalle, 2018, p. 129). Para Forth, as idéias de Nietzsche difundidas pelo periódico francês tiveram um papel muito importante dentro do movimento simbolista na medida em que muitos escritores adotaram as idéias e a linguagem inflamatória de Nietzsche de maneira positiva: articulando seu desejo de ação vital e afirmadora, exemplificada especialmente nos círculos literários anarquistas, entre certos conservadores radicais, e ate mesmo dentro do própria revista, considerada pelo autor como o principal órgão do Simbolismo. Nesse momento entre os intelectuais simbolistas franceses o filósofo foi lido a partir do prisma regeneração cultural, para a qual o pensamento de Nietzsche se tornou catalisador importante (Forth, 1993, p. 110).

A partir do início da Primeira Guerra Mundial, o pensador alemão apesar de continuar figurando nos debates estéticos e literários de grande parte dos escritores na França, começa a ter suas ideias rejeitadas, sendo "acusado de ter incentivado os agressivos e impiedosos germânicos a se lançarem contra os civilizados e cultos franceses" (Frezzatti, 2012, p. 80). Essa rejeição dos franceses pelo pensamento de Nietzsche no inicio do século XX, não ocorre entre os sul-americanos, onde ele continua sendo lido com muito entusiasmo, sobretudo por ser visto como um pensador francófilo e de grande aceitação entre os franceses. Essa ampla difusão que sua filosofia teve no ambiente francês durante o fim do século XIX e inicio do século XX, acabou gerando grande repercussão nos países de cultura francófona, dentre eles a Argentina .

\section{A InfluênCia da Revista na America do Sul}

A revista/editora Mercure de France, do mesmo modo que diversas outras revistas culturais francesas como a Revue dês Deux Mondes, La Plume, La Revue Blanche, durante o período entre 1880-1914, passou por um momento de grande expansão editorial e ampliação do seu publico leitor para outros países e continentes. Assim como outras revistas francesas, contava com assinantes na America, que pagavam 30 pesos pela anualidade desde o exterior, um valor alto se comparado com outros periódicos similares (Merbilhaá, 2015, p. 263-264). Segundo o relato de Sáenz Hayes, integrante da Academia Argentina de Letras, podemos ter a noção de como eram importadas essas edições no ano de 1915:

Evoco aquellos, felices días de mi mocedad - felices e ingenuos. Esperábamos la llegada de un lentísimo transatlántico con ejemplares del Mercure de France, para deleitarnos con las reflexiones sobre la Vida y los Diálogos sobre las cosas del pasado (1965, p. 238).

O artigo escrito em ocasião da morte de Remy de Gourmont, um dos (re)fundadores da editora francesa, revela como haviam muitos leitores argentinos dos periódicos franceses no inicio do século passado. Seguida pela Revue de Deux Mondes, a Mercure de France, no inicio do século XIX, era a revista que mais circulava na America Latina (Merbilhaá, 2016, p. 9). O periódico parisiense teve tanto êxito no continente que, 
em 1897, foi criada a coluna de letras hispano-americanas na qual colaboraram alguns escritores latinoamericanos. Para um intelectual hispano-americano, ser publicado sob o selo de uma editora parisiense significava conseguir fama e reconhecimento em seu próprio país, sobretudo quando os públicos leitores de cada nação -e esse era o caso dos escritores latino-americanos - não permitiam o desenvolvimento de uma vida cultural e artística se comparada aos países europeus (Villegas, 2007, p. 42-43). Nos primeiros anos do século XX, parte importante da impressão da revista era enviada ao Novo Continente. Durante muitos anos, foi a Mercure de France a revista mais lida e comentada em todos os núcleos cultos das cidades grandes ou não da America Latina (Asturias, 1988, p.749). Paris, nesse momento, havia se transformado na Meca cultural dos sul-americanos (Rukser, 1962, p. 40). Nesse sentido, podemos afirmar que a publicação de um autor por uma editora parisiense no final do século XIX e início do século XX, para os escritores argentinos, era uma forma de adquirir capital financeiro e simbólico. $\mathrm{O}$ sucesso das publicações francesas na Argentina também se deu em função da grande quantidade de leitores imigrantes franceses que existiam na cidade de Buenos Aires nesse período. Em 1887, por exemplo, das 430.000 pessoas que habitavam a capital argentina, 20.031 eram francesas, com um nível de alfabetização em torno de 88 por cento (Gruss, 2017).

A Mercure de France também serviu de modelo para as revistas culturais que circularam em Buenos Aires no final do século XIX e inicio do século XX, tais como a revista El Mercurio de la America e a Nosotros. A primeira criada e dirigida pelo jornalista argentino Eugenio Diaz Romero em 1898 refletia uma grande influencia da revista francesa. Segundo Gomez Carrillo, cronista da Mercure de France:

Sin embargo, hubo uno que entre ellos, por su importancia e influencia, habría merecido una larga vida. Me refiero al Mercurio de América, de Buenos Aires, que por imitación del Mercure de France fundó un grupo de jóvenes escritores. En la forma, la división de las secciones, los temas y aun las letras de imprenta era idéntico a la revista francesa (Gomez Carillo, 1907, p. 180-181).

Esta ultima, fundada por Alfredo Bianchi y Roberto Giusti em 1907, segundo Miranda Lida, aspirava ser uma revista cultural de vocação americanista de acordo com o modelo das revistas francesas dos oitocentos, tendo como inspiração as já citadas Revue des Deux Mondes, e a própria Mercure de France (Lida, 2015, p. 80). Para a autora, não se tratavam de meras copias, pelo contrário, a revista Nosotros foi reconhecida pela Mercure de France como capaz de sustentar seus critérios estéticos e literários autônomos e independentes das revistas francesas. Giusti apresentou-a como "Revista Mensual de Literatura-Historia-Arte-Filosofia". Como já foi mencionada anteriormente, a revista Nosotros publicou a obra Ecce Homo de Nietzsche e entre os anos de 1907 a 1926 publicou inúmeros artigos introduzindo seu pensamento ao leitor argentino.

\section{Conclusão}

Podemos afirmar que a mediação francesa foi fundamental para a difusão de Nietzsche no ambiente intelectual argentino, na medida em que essas edições francesas possuíam capital simbólico reconhecido entre muitos leitores da América do Sul e estavam vinculadas às editoras, cujo projeto estético/literário se coadunava com as propostas modernistas e simbolistas dos intelectuais do subcontinente. O filósofo alemão, ao mesmo tempo em que atraía a atenção dos leitores argentinos por ser uma alternativa ao positivismo e ao evolucionismo, também foi alvo de interesse, em grande medida, por ter sido traduzido e divulgado pelas revistas e editoras francesas, as quais gozavam de um grande prestígio nos centros intelectuais latinoamericanos.

Segundo Bourdieu (2002), os textos circulam sem seus contextos de produção e acabam sendo lidos a partir de contextos muito diferentes do original. Nesse sentido, o campo de recepção condiciona o sentido e a função de uma obra estrangeira. Essa produção de sentido, no entanto ocorre também em função de diversas operações de seleção efetuadas nos países de destino, como, por exemplo, o que será traduzido, por quem, o que será publicado, como, com que marcas, por que editora, coleção, quem serão os resenhistas 
e comentadores, como será o lançamento, a divulgação, a distribuição, o que, por sua vez, envolve um conjunto diversificado de agentes e de interesses (Bourdieu, 2002). Esses aspectos em geral não são levados em conta na pratica de uma historia da leitura ou recepção, apesar de interferirem decisivamente nas leituras, interpretações e mal-entendidos dos textos.

A primeira etapa da recepção de Nietzsche na Argentina foi caracterizada por uma mediação das editoras e dos periódicos franceses, que possuíam um grande público leitor na América do Sul. Essa intermediação francesa se deu, sobretudo, através dos artigos comentando e resenhando o filósofo publicados por Henri Albert nas revistas publicadas em Paris, que eram exportadas para o continente sul-americano e das primeiras traduções das obras do filósofo alemão para o francês. Apesar das edições espanholas terem circulado bastante no inicio do século XX, essas eram traduzidas em grande parte das edições da Mercure de France e outras editoras francesas. Numa época em que o idioma francês gozava de enorme capital de distinção no mundo dos livros e as editoras parisienses possuíam uma posição privilegiada no campo editorial, as traduções das obras de Nietzsche para o francês, assim como artigos de comentadores franceses sobre o seu pensamento, acabaram gerando um grande interesse entre os intelectuais argentinos.

\section{FONTES}

Dario, R. (2 de abril de 1894). Los raros, Filosofos finiseculares. La Nación

Ingenieros, J. (2011). El hombre mediocre. Buenos Aires, Argentina: Capital Intelectual.

Rojas, R. (2010 [1909]). La restauración nacionalista. Presentación de Darío Pulfer. La Plata, Argentina:

UNIPE.

Suplementos de Nosotros. Números extraordinarios: Florencio Sánchez, enero-feb. 1908, N6-7; Rubén

Darío, feb. 1909.

\section{BIBLIOGRAFÍA}

Aguado, A. (2006). Políticas editoriales e impacto cultural en la Argentina (1880-2000). Información, Cultura y Sociedad, 15.

Albert, H. (1892). Les livres. La Revue indipendante, 131.

Albert, H. (8 May. 1893). Un manifeste litteraire Allemand. Mercure de France.

Albert, H. (1 Feb. 1893). Friedrich Nietzsche. Mercure de France.

Asturias, M. A. (1988). Paris 1924-1933: Periodismo y creacion literária. Edicion critica. Madrid, España: Colección Archivos.

Bourdieu, P. (2002). Las condiciones sociales de circulación de las ideas. Em Intelectuales, politicay poder. Buenos Aires, Argentina: Eudeba.

Caeiro, O. (2015). Literatura argentina comparada. Córdoba: Alción Editora.

Castellano, P. (2015). Francia, España, Hispanoamérica: Estrategias editoriales ante el mercado internacional del libro (1900-1914). Recuperado de https://ccec.revues.org/5546

Chartier, R. (1994). Libros, lecturas y lectores en la Edad Moderna. Madrid, España: Alianza Universidad.

Cragnolini, M. (2001). Nietzsche em la Argentina entre 1880-1945. Intantes y Azares, 1.

Gómez Carrillo, E. (1 marzo de 1907). Lettres espagnoles. Mercure de France.

Diethe, C. (2006). Historical Dictionary of Nietzscheanism (Historical Dictionaries of Religions, Philosophies, and Movements Series). Lanham, Maryland, Toronto, Playmouth, UK: Scarecrow Press.

Drews, P. (2014). Nietzsche no Uruguai, 1890-1910. Cadernos Nietzsche, 1(35), 183-202.

Frezzatti, W. (2012). A recepção de Nietzsche na França: da Revue philosophique de la France et de l' Étranger ao período entreguerras. Cadernos Nietzsche, 1(30). 
Forth, C. (1993). Nietzsche, Decadence, and Regeneration in France, 1891-95. Journal of History of Ideas, 54(1), 97-117.

Gruss, V. (2017). Le Courrier de La Plata, Diario de la colectividad francesa rio-platense. Temas de Historia Argentina y Americana, (8), 95-141.

Heidegger, M.(2014). Nietzsche. Rio de Janeiro, Brasil: Forense Universitária.

Lida, M. (2015). El grupo editor de la revista Nosotros visto desde dentro. Argentina, 1907-1920. Historia Critica, 58(58), 77-94.

Lomeu Teixeira Barroso, A. V. (2013). Um Nietzsche a Brasileira, a recep̧̧ão do pensamento nietzschiano em intelectuais modernistas (1890-1930). Dissertação de mestrado em Historia da UFRRJ.

Lopez, C. (2013). A revista Mercure de France: Literatura e novas perspectivas na década de 1890. En X Seminário Internacional de História da Literatura (PUC-RS), Rio Grande do Sul, pp. 1-9.

Merbilhaá, M. (2016). La red de revistas latinoamericanas en París (1907-1914). Condiciones y mediaciones. Orbis Tertius, 21(24). Recuperado de https://www.orbistertius.unlp.edu.ar/article/download/OTe016/7653

Merbilhaá, M. (2015). Emergencias de la mediación intelectual. La Revista América. Anales de Literatura Hispanoamericana, (44), 253-280.

Pastormerlo, S. (2005). El nacimiento de un mercado editorial en Buenos Aires, 1880-1890. Orbis Tertius, 10(11).

Ponce, A. (1948). José Ingenieros: su vida y obra. Buenos Aires, Argentina: Iglesias y Matera.

Rocca, P. (2012). Editar en el Novecientos (Orsini Bertani y algunos problemas de las culturas material y simbólica). Orbis Tertius, 17(18). Recuperado de http://www.memoria.fahce.unlp.edu.ar/art_revistas/pr.5378/pr.5378.p df

Rojas, R. (2010) [1909]. La Restauración Nacionalista. La Plata, Argentina: Unipe.

Rukser, U. (1960). Nietzsche y el mundo hispánico, Humboldt / Spanische. Ausgabe, 1(1), 55-60.

Sáenz Hayes, R. (1965). Boletin de la Academia Argentina de Letras.

Sanchez, S. (2013). Nietzsche no Rio da Prata (1900-1950). Cadernos Nietzsche, (33), 61-88.

Sora, G. (2011). El libro y la edición en Argentina Libros para todos y modelo hispano-americano. Políticas de la Memoria, (11).

Schmigalle, G. (2018). Darío, lector de Nietzsche. Anales de Literatura Hispanoamericana, (47), 125-140.

Sobejano, G. (2007). Nietzsche en España. Madrid, España: Gredos.

Sobejano, G. (2009). Sobre la recuperación de Nietzsche. Alicante, España: Biblioteca Virtual Miguel de Cervantes.

Tarcus, H. (2007). Marx en la Argentina. Buenos Aires, Argentina: Siglo XXI.

Valinoti, B. C. (2016). Construyendo el mundo editorial en Argentina en los inicios del siglo XX. Anuario CEEED, (8).

Verbaere, L. (2008). Les traductions françaises de Nietzsche en Europe. Études Germaniques, 63(3), 601-621.

Villegas, J-C. (2007). Paris, capitale littéraire de l'Amérique latine. Dijon, Francia: Université de Dijon.

\section{Notas}

1 Nosso trabalho se apóia nas contribuiçóes teóricas de Pierre Bourdieu (2002), Roger Chartier (1994) que consideram as reflexões sobre a historia do livro, da circulação de textos e das edições como indispensáveis para a historia intelectual e da recepção de idéias. A idéia desse artigo ocorreu após as contribuições e provocações dos professores Alejandro Dujovne, Jose Luis de Diego e Fabio Esposito, durante o curso de verão "Diagnóstico y debates en la edición contemporânea" em 2016, ministrado por eles.

2 Em função das adulterações de seus textos realizadas por sua irmã, Elisabeth Foerster, e sua vinculação com o nazismo, o filósofo alemão teve uma enorme discussão em torno da necessidade de reedições de suas obras. A partir de 1960, Mazzino Montinari e Giorgio Colli dão inicio ao projeto de reeditar a coleção inteira de Nietzsche, no que foi chamado de edição critica e completa de suas obras, empreendimento que ate hoje serve como referencia confiável para os estudiosos do seu pensamento. 
3 Tal fenômeno também se evidencia no Uruguai e no Brasil como nos demonstra o artigo Nietzsche no Uruguai, 1890-1910, publicado por Pablo Drews, e a dissertação de mestrado de Antonio Lomeu, Um Nietzsche a Brasileira: intelectuais receptores do pensamento nietzschiano 1890-1930

4 Por outro lado, Thomas Ward, em seu artigo Los Posibles Caminos de Nietzsche en el Modernismo considera que as primeiras traduções argentinas de Nietzsche datam da década de 1920, Opiniones (1922) e Wagner combatido por Nietzsche (1924).

5 A obra que nos referimos é Nietzsche, Federico. Obras Completas, vols 11-13, trad. E. Overjero y Maury, Vols, 14-15, Madrid, Aguilar, 1932-51.

6 Mais adiante, veremos como a Mercure de France se dedicava a tradução de obras literárias e criticas artísticas.

$7 \mathrm{O}$ titulo original em alemão é AristokratischerRadicalismus.EincAbhandlungüber Friedrich Nietzsche» Deutsche Rundschau, 1890, Vol. LXIII, pp. 67-8.

8 Há, no entanto, referencia a um volume de seis ensaios, publicados em diferentes revistas com o titulo de Homens e obras, de autoria de Georg Brandes. Cf. Brandes, Georg, Etude accompagnée dês lettres de Nietzsche à Brandes, Stalkeréditeur, Paris, 2006.

9 De acordo com Oscar Caeiro (2014), a apropriação literária do filósofo se deu principalmente no sentido da influencia do seu estilo e suas reflexões preencheram de conteúdo fala de personagens de romances argentinos.

10 Também foram publicadas pela Mercure de France: Par de là le bien et le mal (1898), traduzida por L. Weiscopf e Georges Art, e editada por Henri Albert; Humain, trophumain I (1899), traduzida por Alexandre-Marie Desrousseaux; e L' Origine de la tragédie (1901), traduzida por Jean Marnold e Jacques Morland. 